\title{
Semi-Analytical Finite Strip Transfer Matrix Method for Buckling Analysis of Rectangular Thin Plates
}

\author{
Li-Ke Yao, Bin He, Yu Zhang, and Wei Zhou \\ Mechanics Department, Nanjing Tech University, Nanjing, China \\ Correspondence should be addressed to Bin He; hebin123@njtech.edu.cn
}

Received 16 June 2015; Revised 28 September 2015; Accepted 22 October 2015

Academic Editor: Alessandro Gasparetto

Copyright (C) 2015 Li-Ke Yao et al. This is an open access article distributed under the Creative Commons Attribution License, which permits unrestricted use, distribution, and reproduction in any medium, provided the original work is properly cited.

\begin{abstract}
Plates and shells are main components of modern engineering structures, whose buckling analysis has been focused by researchers. In this investigation, rectangular thin plates with loaded edges simply supported can be discretized by semi-analytical finite strip technology. Then the control equations of the strip elements of the buckling plate will be rewritten as the transfer equations by transfer matrix method. A new approach, namely semi-analytical Finite Strip Transfer Matrix Method, is developed for the buckling analysis of plates. This method requires no global stiffness matrix of the system, reduces the system matrix order, and improves the computational efficiency. Comparing with some theoretical results and FEM's results of two illustrations (the plates and the ribbed plates) under six boundary conditions, the method is proved to be reliable and effective.
\end{abstract}

\section{Introduction}

Buckling analysis is one of the important steps in the design of thin-walled structures which can be applied in different branches of engineering, including shipbuilding, civil architecture, and mechanical construction [1]. Thin plate, a main kind of thin-walled structure, is widely utilized to lighten engineering structures as well as save materials [2]. The reliability of one single plate lies in its stability chiefly, which has been studied by experimental or mathematical means [3].

In the early works, the vibration and buckling performances of rectangular plates loaded by in-plane hydrostatic forces for a wide variety of aspect ratios, boundary conditions, and loading magnitudes have been analyzed by numerical technology [4]. The solutions of the differential equations of the buckling Mindlin plate are obtained in discrete forms by applying numerical integrations [5]. And extensive numerical results have been presented for the critical buckling loads of simply supported, rectangular composite plates subjected to five types of loading conditions: (1) uniaxial, (2) hydrostatic biaxial, (3) compression-tension biaxial, (4) positive shear, and (5) negative shear [6]. By introducing an unified analytical solution technique for a multitude of combinations of boundary conditions, an analytical method is presented for the problem of elastic buckling of orthotropic rectangular plates [7]. If the biharmonic operator in the buckling control equations of rectangular plates is reduced by performing the Laplace's operator and the finite difference method, the buckling load of the plate can be investigated [8]. Up to now, many methods have been used to analyze the buckling problems of rectangular plates, such as the extended Kantorovich method [9], differential quadrature procedures [10], asymptotic finite strip method [11], block GMRES method [12], firstorder shear deformation meshless method [13], radial point interpolation method [14], untruncated infinite series technology [15], discrete singular convolution approach [16], and hierarchical Rayleigh-Ritz and finite element method [17].

Among these methods, finite element method is a powerful tool for engineering analysis, while the choices of the elements and the mesh sizes have significant influences on the results of buckling analysis [18]. When calculating the buckling problems of regular geometry shape structures, finite strip method can be regarded as an efficient way. And the arbitrary shaped plate may be discretized as many strip elements by the subparametric mapping concept [19]. To consider the transverse shear effect, the spline strip method has been proposed to analyze the buckling behaviors of rectangular Mindlin plates with linearly tapered thickness 
in one direction [20]. The buckling stresses and natural frequencies of rectangular laminated plates with arbitrary layups and general boundary conditions can be predicted by the improved spline finite strip, which combines the superstrip concept [21]. Then a higher-order shear deformable plate finite strip element is developed and employed to investigate the critical buckling loads of composite laminated plates [22]. The spline finite strip method and multilevel substructuring procedures are combined for the buckling stress analysis of composite laminated, prismatic shell structures with general boundary conditions [23]. Buckling mode localization in ribstiffened plates with randomly misplaced stiffeners is studied by finite strip method [24]. Notably, a comprehensive review of the finite strip method for structural analysis is given [25]. A layerwise B-spline finite strip method is developed for free vibration analysis of truly thick and thin composite laminated plates [26]. And a finite strip Fourier p-element is developed to analyze the natural vibration characteristics of the thin plate [27]. Based on the concept of the semienergy approach, the finite strip method can be proposed to analyze the buckling [28], postbuckling [29], dynamic buckling behaviors of the laminated plates [30], and stability phenomena of cylindrical shell structures [31]. The harmonic series satisfying the boundary conditions in the loaded ends of thin-walled members are generally employed in SemiAnalytical Finite Strip Transfer Matrix Method (SAFSM) [32]. And the buckling stress of the cold-formed sections can be analyzed by SAFSM [33], which has been widely used in computer softwares (such as THIN-WALL [34], CUFSM [35]) to develop the signature curves [36] of the buckling stress versus buckling half wavelength for thin-walled members. Furthermore, the constrained finite strip method innovated from SAFSM is developed and applied in cold-formed steel design [37]. Generalized constrained finite strip method for thin-walled members with arbitrary cross-sections can be used to analyze secondary modes [38] and primary modes [39]. The impacts of basis, orthogonalization, and normalization in constrained finite strip method are discussed for stability solution of open thin-walled members [40].

Transfer matrix method has been developed as an effective tool for vibration analysis of engineering structures, especially for chain connected system from topological perspective [41]. Then a combined finite element transfer matrix method is developed to study the statics [42] and dynamics [43] of structures. Later a new transfer matrix method based on the boundary element and transfer matrix technology is proposed for the vibration analysis of two-dimensional plate acted by uniform [44] and concentrated [45] loads. By introducing the numerical integration, nonlinear dynamics of structures [46], multi-rigid-body system [47], and multiflexible-body system [48] can be dealt with by transfer matrix method. And a procedure which combines multiport transfer matrices and finite elements has been developed to resolve the acoustic phenomena of automotive hollow body networks [49]. It should be noted that three references enlighten us to start this investigation. The buckling analysis of the plate with built-in rectangular delamination has been implemented by strip distributed transfer function method [50]. And the transfer matrix method can be used to analyze

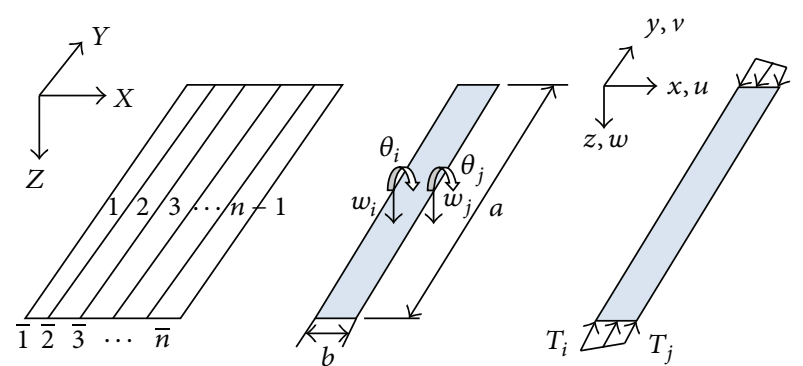

Figure 1: Coordinates, degree of freedom, and loads of a typical strip.

the instability in unsymmetrical rotor-bearing systems [51] and tall unbraced frames [52].

Here by combining two powerful methods of the semianalytical finite strip and the transfer matrix, an efficient technology named semi-analytical Finite Strip Transfer Matrix Method (FSTMM) for the buckling analysis of plates is developed. The text is organized as follows: In Section 2, the general theorem of the semi-analytical finite strip for buckling analysis of plates is shown. Section 3 presents semianalytical Finite Strip Transfer Matrix Method for buckling analysis. In Section 4, some results calculated by FSTMM and other methods are given, which can validate the proposed method. The conclusions are included in Section 5.

\section{The Semi-Analytical Finite Strip Analysis}

2.1. Degree of Freedom and Shape Function. In classical Kirchhoff plate theory, the membrane or in-plane translations are neglected and only the $z$-axis's translation $w$ and the $y$ axis's rotation $\theta$ are considered as local displacements [1]. The global coordinate system $(X, Y, Z)$ and local coordinate system $(x, y, z)$ are actually the same in the plate model. In finite strip method (FSM), a thin plate, as shown in Figure 1, can be divided into many strip elements.

We introduce a numbering system of finite strip model shown in Figure 1. The total number of nodal lines is $n$; therefore, the total number of strips is $n-1$. Generally, one internal nodal line is always connected with two strips, while the first and last nodal lines are only connected with one strip. This numbering system will be used to depict the state vector of the nodal line and the transfer matrix of the strip in Section 3.

Here the plate is assumed to have two opposite loaded edges with the simply supported boundary; analytical trigonometric functions that satisfy the simply-simply supported boundary condition of the loaded edges can be given to express the transverse deflection of the plate along the longitudinal direction [35, 37]:

$$
Y_{p}(y)=\sin \frac{p \pi y}{a}, \quad p=1,2,3, \ldots, n,
$$

where $p$ is the half-wave number, which also stands for certain half wavelength along the longitudinal direction, $\pi$ is the circumference ratio, $y$ is the longitudinal coordinate in local system, $a$ is the length of the plate. 
Four cubic polynomials that satisfy the boundary condition can be selected as the shape function matrix to depict the out-of-plane displacement of the plate strip along the transverse direction, namely $[39,40]$,

$$
\begin{aligned}
& \mathbf{N}(x) \\
& =\left[1-\frac{3 x^{2}}{b^{2}}+\frac{2 x^{3}}{b^{3}} x-\frac{2 x^{2}}{b}+\frac{x^{3}}{b^{2}} \frac{3 x^{2}}{b^{2}}-\frac{2 x^{3}}{b^{3}} \frac{x^{3}}{b^{2}}-\frac{x^{2}}{b}\right],
\end{aligned}
$$

where $b$ is the width of the strip as shown in Figure 1 and $x$ is the coordinate along the width direction in local system.

Then the transverse deflection $w$ of any points $(x, y)$ in the strip can be denoted by the so-called nodal line displacement vector $\boldsymbol{\delta}^{p}$ and shape function matrix $\mathbf{N}_{p}(x, y)$ :

$$
w(x, y)=\sum_{p=1}^{m} \mathbf{N}_{p}(x, y) \boldsymbol{\delta}^{p},
$$

where $\mathbf{N}_{p}(x, y)$ can be denoted as the production of the shape functions of (1) and (2),

$$
\mathbf{N}_{p}(x, y)=\mathbf{N}(x) Y_{p}(y),
$$

$\boldsymbol{\delta}^{p}$ can be defined as the $z$-axis's translation $w$ and the $y$-axis's rotation $\theta$ of the two nodal lines in one strip,

$$
\boldsymbol{\delta}^{p}=\left[\begin{array}{llll}
w_{i}^{p} & \theta_{i}^{p} & w_{j}^{p} & \theta_{j}^{p}
\end{array}\right]^{T}
$$

the subscripts $i$ and $j$ denote two edges of one strip, which are connected with other strips or are the boundaries of the plate respectively, and $m$ is the maximum half-wave number as well as order of modal employed in the analysis, which is a finite positive integer.

2.2. Fundamental Stiffness Matrix. So far, many plate theories have been developed by engineers and researchers [2]. The Kirchhoff plate theory is a classical and simple one, which will be used in this investigation. It must be noted that other plate theories can be applied in the proposed method if the elastic deformation energy and the nodal line displacement vector are modified accordingly. The bending strain vector of middle plane in Kirchhoff plate can be defined as

$$
\boldsymbol{\varepsilon}_{B}=-\left[\begin{array}{lll}
\frac{\partial^{2} w}{\partial x^{2}} & \frac{\partial^{2} w}{\partial y^{2}} & 2 \frac{\partial^{2} w}{\partial x \partial y}
\end{array}\right]^{T} .
$$

We substitute (3) into above equation, the bending strain vector can be expressed by the nodal line displacement vector and shape function matrix; namely,

$$
\boldsymbol{\varepsilon}_{B}=\sum_{p=1}^{m} \mathbf{N}_{p}^{\prime \prime} \boldsymbol{\delta}^{p}
$$

where $\mathbf{N}_{p}^{\prime \prime}=-\left[\begin{array}{lll}\partial \mathbf{N}_{p}^{T} / \partial x^{2} & \partial \mathbf{N}_{p}^{T} / \partial y^{2} & 2\left(\partial \mathbf{N}_{p}^{T} / \partial x \partial y\right)\end{array}\right]^{T}$ is a $(3 \times$ 4) matrix that gives the relationship between the strain vector $\boldsymbol{\varepsilon}_{B}$ and the nodal line displacement vector $\boldsymbol{\delta}^{p}$. As to general linear elastic material, the elastic deformation energy can be expressed as

$$
U=\frac{1}{2} \int_{V} \boldsymbol{\varepsilon}^{T} \boldsymbol{\sigma} \mathrm{d} V
$$

where $\boldsymbol{\varepsilon}$ and $\boldsymbol{\sigma}$ denote strain and stress vectors, respectively, $V$ is the volume of the material. According to Kirchhoff plate theory with constant thickness, the elastic bending deformation energy of (8) can be rewritten as

$$
U=\frac{1}{2} \int_{0}^{a} \int_{0}^{b} \boldsymbol{\varepsilon}_{B}^{T} \mathbf{D}_{B} \boldsymbol{\varepsilon}_{B} \mathrm{~d} x \mathrm{~d} y
$$

where $\mathbf{D}_{B}$ is an elastic constant matrix of the material with a dimension of $(3 \times 3)$, which is related to the thickness of the plate $[1,2]$. We substitute (4) into (9), the new deformation energy formula can be obtained as follows:

$$
U=\frac{1}{2} \sum_{p=1}^{m} \sum_{q=1}^{m} \boldsymbol{\delta}^{p T} \mathbf{k}_{e}^{p q} \boldsymbol{\delta}^{q}
$$

where the elastic stiffness matrix of the strip can be concisely expressed in a form

$$
\mathbf{k}_{e}^{p q}=\int_{0}^{a} \int_{0}^{b} \mathbf{N}_{p}^{\prime \prime T} \mathbf{D}_{B} \mathbf{N}_{q}^{\prime \prime} \mathrm{d} x \mathrm{~d} y .
$$

Above elastic stiffness is a $(4 \times 4)$ matrix. When the parameters $p, q$ vary, the elastic stiffness changes accordingly. However, to the case of $p \neq q$, elastic stiffness matrix always equals zero, that can be found by integrating (11). The reason is that the shape function $\mathbf{N}_{p}^{\prime \prime}$ is orthogonal about the elastic constant matrix $\mathbf{D}_{B}$, which can be expressed as

$$
\begin{aligned}
& \mathbf{k}_{e}^{p q} \\
& = \begin{cases}\int_{0}^{a} \int_{0}^{b} \mathbf{N}_{p}^{\prime \prime T} \mathbf{D}_{B} \mathbf{N}_{q}^{\prime \prime} \mathrm{d} x \mathrm{~d} y, & p=q=1,2,3, \ldots, m, \\
0, & p \neq q .\end{cases}
\end{aligned}
$$

As shown in Figure 1, the strip is loaded with linearly varying edge tractions. The in-plane compressive loads can be expressed as

$$
T_{x}=T_{i}-\left(T_{i}-T_{j}\right) \frac{x}{b}
$$

where $T_{i}, T_{j}$ are the forces in two edges of the strip, $b$ is the width of the strip as shown in Figure 1, and $x$ is the transverse coordinate. Similar to the deduction of the elastic stiffness matrix, the $(4 \times 4)$ geometric stiffness matrix caused by inplane compressive loads can be obtained [34, 35]:

$$
\mathbf{k}_{g}^{p q}=\int_{0}^{a} \int_{0}^{b}\left(T_{i}-\left(T_{i}-T_{j}\right) \frac{x}{b}\right) \mathbf{N}_{p}^{\prime T} \mathbf{N}_{q}^{\prime} \mathrm{d} x \mathrm{~d} y,
$$

where $\mathbf{N}_{p}^{\prime}=\mathbf{N}(x)\left(\partial Y_{p}(y) / \partial y\right)$ is a $(1 \times 4)$ matrix. It can be proofed that $\mathbf{N}_{p}^{\prime}$ includes an orthogonal system of functions; namely, 


$$
\mathbf{k}_{g}^{p q}= \begin{cases}\int_{0}^{a} \int_{0}^{b}\left(T_{i}-\left(T_{i}-T_{j}\right) \frac{x}{b}\right) \mathbf{N}_{p}^{\prime T} \mathbf{N}_{q}^{\prime} \mathrm{d} x \mathrm{~d} y, & p=q=1,2,3, \ldots, m, \\ 0, & p \neq q .\end{cases}
$$

The solution of the buckling problems can be deduced by the orthotropic condition of (12) and (15) conveniently. For other boundary conditions, different analytical functions can be selected to describe the buckling shape of the strip [53]. These will be discussed in the successive related papers.

\section{Semi-Analytical Finite Strip Transfer Matrix Method for Buckling Analysis}

3.1. Control Equations of Strip Element. In both finite element transfer matrix method and boundary element transfer matrix method, transfer equations of the given substructure can be deduced by the control equations of this substructure which consider the interaction forces between this substructure and other structures. As to the proposed Finite Strip Transfer Matrix Method, the strip element can be regarded as the substructure.

The control equations of the buckling strip can be obtained by virtual work principle $[1,2]$ :

$$
\left(\mathbf{k}_{e}^{p p}+\mathbf{k}_{g}^{p p}\right) \boldsymbol{\delta}^{p}=\mathbf{R}^{p},
$$

where $\mathbf{k}_{e}^{p p}$ is the elastic stiffness matrix of (11), $\mathbf{k}_{g}^{p p}$ is the geometric stiffness matrix as shown in (14), $\boldsymbol{\delta}^{p}$ is the nodal line displacement vector can be defined by (5), $p$ is the half-wave number of the buckling strip shape, and $\mathbf{R}^{p}$ can be regarded as the generalized internal forces acted on the strip that can be denoted as

$$
\mathbf{R}^{p}=\left[\begin{array}{llll}
F_{i}^{p} & M_{i}^{p} & F_{j}^{p} & M_{j}^{p}
\end{array}\right]^{T},
$$

where $F_{i}^{p}\left(\right.$ and $F_{j}^{p}$ ) is the generalized internal force associated with the transverse deflection $w_{i}^{p}$ (and $w_{j}^{p}$ ) of the nodal line $i$ (and $j$ ) and $M_{i}^{p}$ (and $M_{j}^{p}$ ) is the generalized internal force associated with the $y$-axis's rotation $\theta_{i}^{p}$ (and $\theta_{j}^{p}$ ) of the nodal line $i$ (and $j$ ), respectively.

Assuming $T_{0}(x)$ as the initial axial force, the real axial forces in the geometric stiffness matrix can be expressed as

$$
T(x)=\lambda T_{0}(x),
$$

where $\lambda$ is the buckling coefficient. So the geometric stiffness matrix $\mathbf{k}_{g}^{p p}$ can be rewritten as the function of the constant geometric stiffness matrix $\left.\mathbf{k}_{g}^{p p}\right|_{T_{0}}$ caused by initial axial force $T_{0}(x)$,

$$
\mathbf{k}_{g}^{p p}=\left.\lambda \mathbf{k}_{g}^{p p}\right|_{T_{0}}
$$

We substitute (19) into (16): the control equations of the strip can be rewritten as follows:

$$
\left(\mathbf{k}_{e}^{p p}+\left.\lambda \mathbf{k}_{g}^{p p}\right|_{T_{0}}\right) \boldsymbol{\delta}^{p}=\mathbf{R}^{p}
$$

To simplify the equations, the coefficient matrix of the nodal line displacement vector $\boldsymbol{\delta}^{p}$ in above equation can be marked by

$$
\mathbf{K}=\mathbf{k}_{e}^{p p}+\left.\lambda \mathbf{k}_{g}^{p p}\right|_{T_{0}},
$$

where both coefficient matrices $\mathbf{k}_{e}^{p p}$ and $\left.\mathbf{k}_{g}^{p p}\right|_{T_{0}}$ are constant values when the loads determined by (18) vary.

3.2. State Vector, Transfer Equations, and Transfer Matrix. During the analysis of transfer matrix method, the state vector of the strip is an important concept that includes two parts: one part describes the configuration of the strip, the other part gives the generalized internal forces acted on the strip by other members in the system. For example, the state vector of the nodal line $i(j)$ can be defined as

$$
\mathbf{Z}_{l, n}=\left[\begin{array}{ll}
\boldsymbol{\delta}_{l}^{p T} & \mathbf{R}_{l}^{p T}
\end{array}\right]_{n}^{T} \quad(l=i, j)
$$

where the first subscript $l$ denotes the number of the nodal lines, the second subscript $n$ denotes the number of the strips, $\boldsymbol{\delta}_{l}^{p}=\left[\begin{array}{ll}w_{l}^{p} & \theta_{l}^{p}\end{array}\right]^{T}$ can be regarded as the generalized displacement vector of the nodal line $l$, and $\mathbf{R}_{l}^{p}=\left[\begin{array}{ll}F_{l}^{p} & M_{l}^{p}\end{array}\right]^{T}$ is the generalized internal force vector acted on the nodal line $l$ correspondingly.

Using the block forms of (22), the control equations (20) can be rewritten as the form of the transfer equations of this strip, which are

$$
\mathbf{Z}_{j, n}=\mathbf{U}_{n}^{e} \mathbf{Z}_{i, n}
$$

where the transfer matrix of the strip $n$ is

$$
\mathbf{U}_{n}^{e}=\left[\begin{array}{cc}
-\mathbf{K}_{12}^{-1} \mathbf{K}_{11} & \mathbf{K}_{12}^{-1} \\
\mathbf{K}_{21}-\mathbf{K}_{22} \mathbf{K}_{12}^{-1} \mathbf{K}_{11} & \mathbf{K}_{22} \mathbf{K}_{12}^{-1}
\end{array}\right],
$$

where the superscript $e$ denotes the strip element, the subscript $n$ denotes the number of the strips, the subscripts $i$ and $j$ denote the two nodal lines of the strip $n$, and $\mathbf{K}_{i j}(i, j=1,2)$ are $(2 \times 2)$ block submatrices that can be determined by $(21)$. Actually, coefficient matrix of (21) can be denoted as

$$
\mathbf{K}=\left[\begin{array}{cc}
\mathbf{K}_{11} & \mathbf{K}_{12} \\
2 \times 2 & 2 \times 2 \\
\mathbf{K}_{21} & \mathbf{K}_{22} \\
2 \times 2 & 2 \times 2
\end{array}\right]
$$

Follow the condition of displacement continuum and the law of action and reaction, the state vectors of the same nodal line in two connected strips can be obtained:

$$
\mathbf{Z}_{l, n+1}=\left[\begin{array}{cc}
1 & 0 \\
0 & -1
\end{array}\right] \mathbf{Z}_{l, n}
$$


TABLE 1: State vectors of nodal lines under various boundary conditions.

\begin{tabular}{lcccc}
\hline Boundary condition (BC) & Simply (s) & Clamped (c) & Free (f) \\
\hline State vectors of nodal lines & $Z_{\mathrm{s}}=\left[\begin{array}{lllll}0 & \theta & F & 0\end{array}\right]^{T}$ & $Z_{\mathrm{c}}=\left[\begin{array}{lllll}0 & 0 & F & M\end{array}\right]^{T}$ & $Z_{\mathrm{f}}=\left[\begin{array}{llll}w & \theta & 0 & 0\end{array}\right]^{T}$ \\
\hline
\end{tabular}

TABLE 2: Eigen-matrices under various boundary conditions.

\begin{tabular}{|c|c|c|c|c|c|c|}
\hline Boundary condition (BC) & SSss & SScc & SSsc & SSfs & SSfc & SSff \\
\hline \multirow{2}{*}{ Eigen-matrix } & {$\left[\begin{array}{ll}U_{12} & U_{13}\end{array}\right.$} & $U_{13} \quad U_{14}$ & {$\left[\begin{array}{ll}U_{12} & U_{13}\end{array}\right.$} & $U_{32} \quad U_{33}$ & $U_{11} \quad U_{12}$ & {$\left[\begin{array}{ll}U_{31} & U_{32}\end{array}\right.$} \\
\hline & $\begin{array}{ll}U_{42} & U_{43}\end{array}$ & $U_{23} \quad U_{24}$ & $U_{22} \quad U_{23}$ & $U_{42} \quad U_{43}$ & $U_{21} \quad U_{22}$ & $\begin{array}{ll}U_{41} & U_{42} \\
\end{array}$ \\
\hline
\end{tabular}

where the subscript $l$ denotes the nodal line number and the subscripts $n$ and $n+1$ denote the order numbers of the two strips which are connected by the nodal line $l$. So the transfer equations between particular nodal lines of conjunctional strips can be obtained by multiplying (23) and (26); namely,

$$
\mathbf{Z}_{l+1, n+1}=\mathbf{U}_{n}^{e, l} \mathbf{Z}_{l, n}
$$

where the transfer matrix of this substructure is

$$
\mathbf{U}_{n}^{e, l}=\left[\begin{array}{cc}
-\mathbf{K}_{12}^{-1} \mathbf{K}_{11} & \mathbf{K}_{12}^{-1} \\
\mathbf{K}_{22} \mathbf{K}_{12}^{-1} \mathbf{K}_{11}-\mathbf{K}_{21} & -\mathbf{K}_{22} \mathbf{K}_{12}^{-1}
\end{array}\right]
$$

where the superscripts $e$ and $l$ denote the strip element and the nodal line.

Introducing the same procedure in the classical transfer matrix method, the overall system transfer equations and the overall transfer matrix $\mathbf{U}_{\text {all }}$ which relate the state vectors at two edges of the plate can be assembled and calculated as

$$
\begin{aligned}
\mathbf{Z}_{n, n-1} & =\mathbf{U}_{\mathrm{all}} \mathbf{Z}_{1,1}, \\
\mathbf{U}_{\mathrm{all}} & =\mathbf{U}_{n}^{e, l} \mathbf{U}_{n-1}^{e, l} \cdots \mathbf{U}_{2}^{e, l} \mathbf{U}_{1}^{e, l} .
\end{aligned}
$$

Three classical boundary conditions are considered in general engineering problems: simply supported, clamped supported, and free edge. Different boundary conditions of the plate can give appropriate limits to specific variables in the state vectors, which are shown in Table 1 . For the buckling analysis of plates with simply-simply (S-S) supported boundary condition of loaded edges in this dissertation, the unloaded edges may sustain six kinds of boundary conditions, which can be expressed by SSss, SScc, SSsc, SSfs, SSfc, and SSff (s, c, and f mean simply, clamped, and free boundary conditions, resp.). Here the capital letters and lowercase letters denote the loaded edges and unloaded edges correspondingly.

Taking the boundary condition SSss, for example, the total transfer equations can be deduced as follows:

$$
\left[\begin{array}{llll}
0 & \theta & F & 0
\end{array}\right]_{L}^{T}=\mathbf{U}_{\text {all }}\left[\begin{array}{llll}
0 & \theta & F & 0
\end{array}\right]_{F}^{T},
$$

where subscripts $F$ and $L$ denote the first and last edges of the plate, $\mathbf{U}_{\text {all }}$ is the overall transfer matrix of the plate. Then the nonzero variables in the state vector of the first edge of the plate have the relationship that can be deduced by (30):

$$
\left[\begin{array}{l}
0 \\
0
\end{array}\right]_{L}^{T}=\left[\begin{array}{ll}
U_{12} & U_{13} \\
U_{42} & U_{43}
\end{array}\right]\left[\begin{array}{l}
\theta \\
F
\end{array}\right]_{F}^{T}
$$

where $U_{12}, U_{13}, U_{42}, U_{43}$ are the elements of $\mathbf{U}_{\text {all }}$. To make the nonzero solution of (31) possible, it must satisfy the following condition:

$$
\operatorname{det}\left(\left[\begin{array}{ll}
U_{12} & U_{13} \\
U_{42} & U_{43}
\end{array}\right]\right)=0 .
$$

Above equation gives the characteristic equation of the buckling plate by the proposed semi-analytical Finite Strip Transfer Matrix Method which can be used to calculate the buckling coefficients. We combine (31) and (27); the buckling mode can be obtained. Eigen-matrices under various boundary conditions are shown in Table 2.

\section{Examples and Analysis}

4.1. Illustrations of Thin Plates. The geometrical and material properties of the plate during the research are as follows: width $b=5 \mathrm{~mm}$, thickness $t=0.1 \mathrm{~mm}$, elastic modulus $E=$ $2 \times 10^{5} \mathrm{~N} / \mathrm{mm}^{2}$, Poisson's ratio $v=0.3$, shear modulus $G=$ $E / 2(1+\nu)$, and initial axial force $T_{0}=\pi^{2} E t^{3} / 12 b^{2}\left(1-v^{2}\right)=$ $7.2305 \mathrm{~N} / \mathrm{mm}$. The length of the plate is a variable parameter which is selected for each boundary condition.

The section is divided into five segments along the loaded edge. The relationship schemas between buckling coefficient $\lambda$ and length-width ratio $\alpha$ of the plate are obtained by the proposed FSTMM, finite element method (FEM), and theoretical analysis. FSTMM's results are compared with theoretical and FEM's results under the boundary conditions of SSss and SSff, as shown in Figures 2(a) and 2(b). For the remaining four boundary conditions, comparisons with FSTMM's and FEM's results are shown in Figures 2(c)-2(f). The six comparisons confirm the reliability of FSTMM for the buckling analysis of the plate.

4.2. Illustrations of Ribbed Plates. Plates with ribs are important engineering components for the load-carrying. Many methods are available to analyze the buckling of prismatic flat and stiffened shell structure [54]. For further application of FSTMM, ribbed plates are discussed below. Notably, due to the application condition of the Kirchhoff plate theory, the thickness of the ribs must be relatively small. Besides, comparisons with FEM's results are used to testify the FSTMM.

4.2.1. Plate with Three Ribs. The material properties are the same as the plate as stated in Section 4.1. The geometrical parameters are as follows. The width of the plate is $5 \mathrm{~mm}$, 


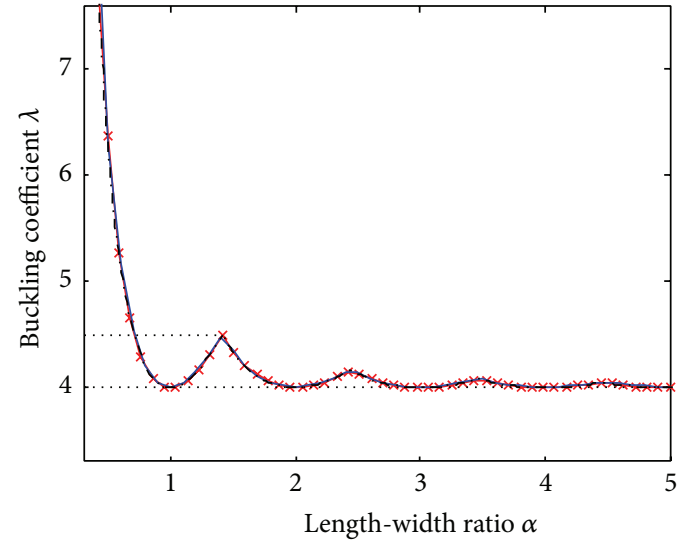

$\rightarrow$ FSTMM results _. - Theoretical results — FEM results

(a) Boundary conditions of SSss

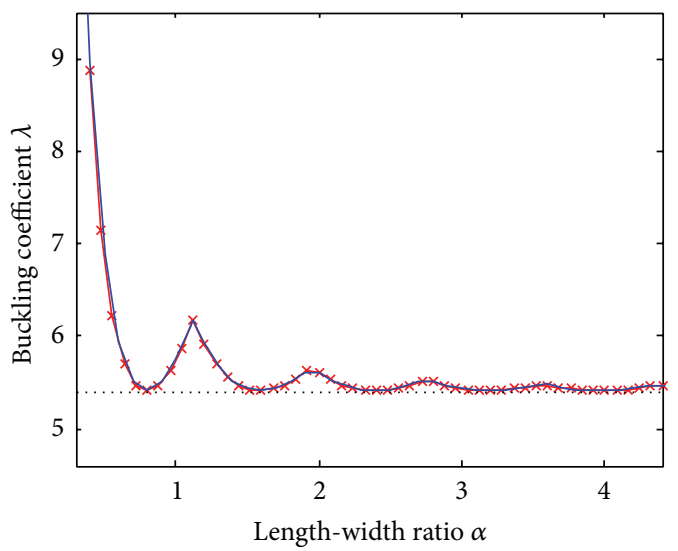

* FSTMM results FEM results

(c) Boundary conditions of SSsc

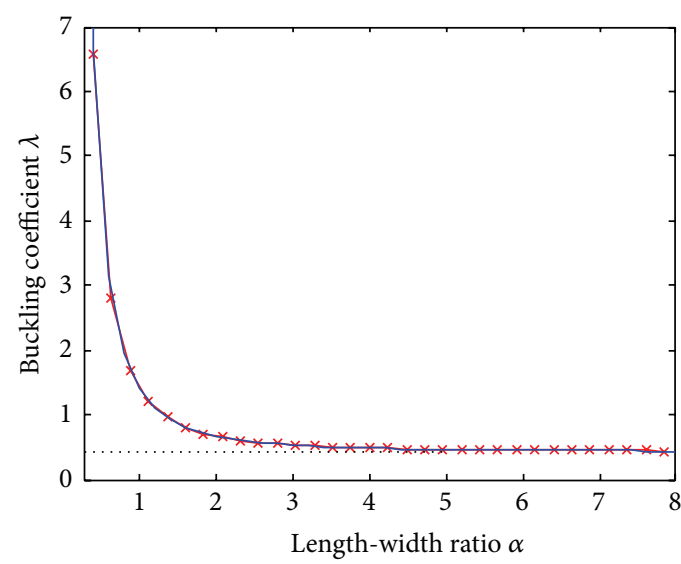

$* \quad$ FSTMM results

$\ldots \ldots \lambda=0.44$

(e) Boundary conditions of SSfs

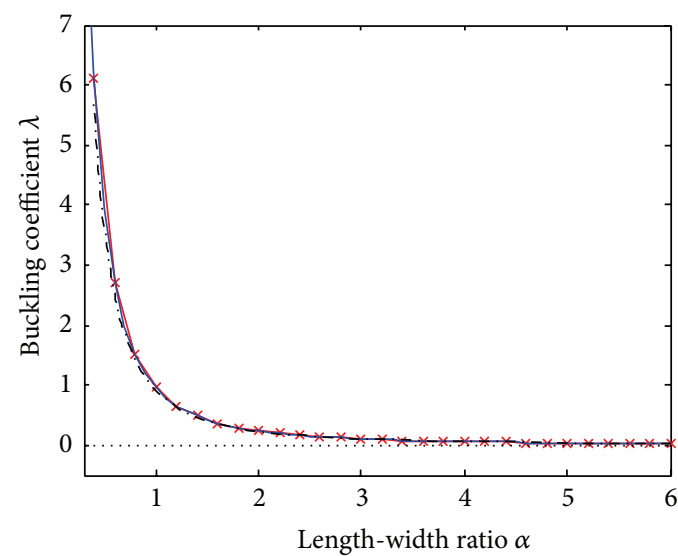

$\star$ FSTMM results ...- Theoretical results - FEM results

(b) Boundary conditions of SSff

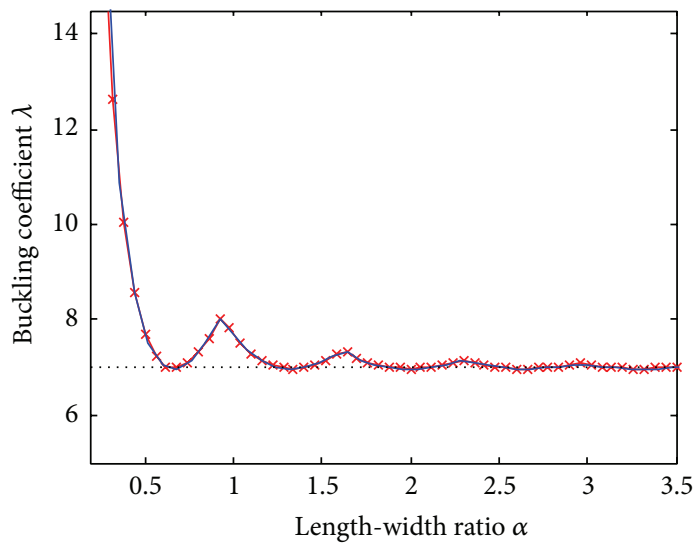

* FSTMM results

… $\lambda=7$

FEM results

(d) Boundary conditions of SScc

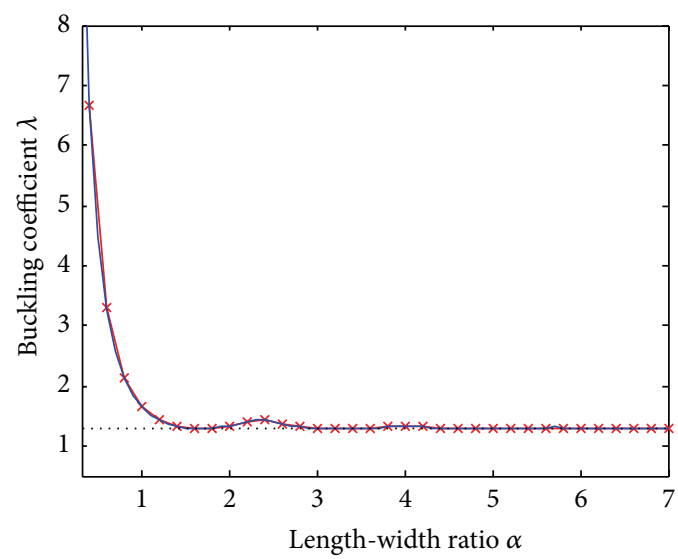
$* \quad$ FSTMM results $\lambda=1.28$
- FEM results

(f) Boundary conditions of SSfc

FIgURE 2: Relations between $\lambda$ and $\alpha$ of the plate. 


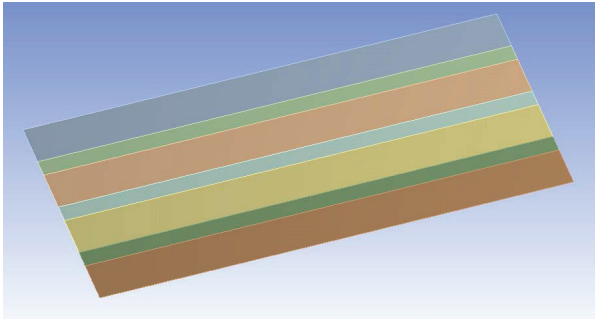

(a) Strip model in FSTMM

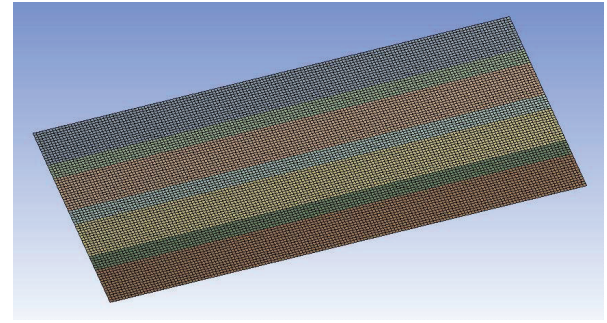

(b) Shell model for FEM

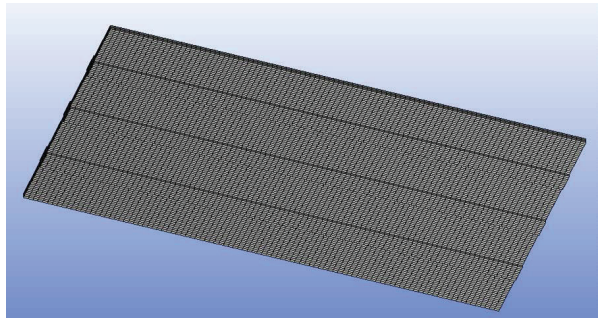

(c) Solid model for FEM

Figure 3: Meshed grids of the plate with three ribs.

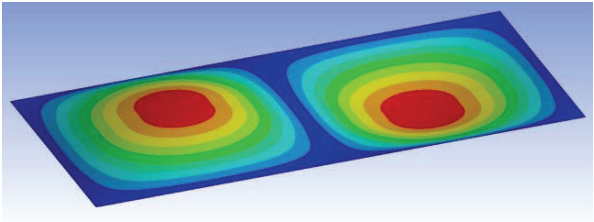

(a) Length-width ratio $\alpha=2$

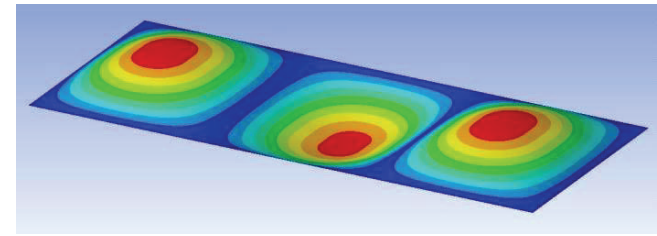

(b) Length-width ratio $\alpha=3.5$

FIGURE 4: Buckling deformation mode of the plate with three ribs and boundary conditions of SSss.

the thickness is $0.1 \mathrm{~mm}$. The ribs are $0.4 \mathrm{~mm}$ in width and $0.2 \mathrm{~mm}$ in thickness. Three ribs are uniformly spaced along the transverse direction, the width of the interval space is $0.95 \mathrm{~mm}$. The length of the plate is a variable parameter ranging from $0.5 \mathrm{~mm}$ to $25 \mathrm{~mm}$. In shell models of FSTMM and FEM, the initial axial force of the plate is $7.2305 \mathrm{~N} / \mathrm{mm}$ and the initial axial force of ribs is $14.461 \mathrm{~N} / \mathrm{mm}$. In solid model of FEM, the initial axial pressure in the cross section is $72.305 \mathrm{MPa}$. Then the loading forces of the shell and solid models are equivalent. Figure 3(a) shows the meshed grid of the plate in FSTMM and the meshed plate in FEM using the shell elements and the solid elements can be given in Figures 3 (b) and 3(c), respectively.

As the plate simply supported in four edges, Figure 4 shows the total buckling deformation of the plate with three ribs when length-width ratios are 2 and 3.5. There are two (or three) half waves in the buckling mode of the length-width ratio $\alpha=2$ (or $\alpha=3.5$ ) shown in Figures 4(a) and 4(b) correspondingly. As a matter of fact, the buckling modes of Figures $4(\mathrm{a})$ and 4 (b) can be obtained by setting the computational parameters of the half-wave number $p=2$ and $p=3$ in the FSTMM with clearer engineering meaning.

The relation curves between buckling coefficient and length-width ratio of the plate with three ribs and boundary conditions of SSss can be calculated by the FSTMM, the FEM

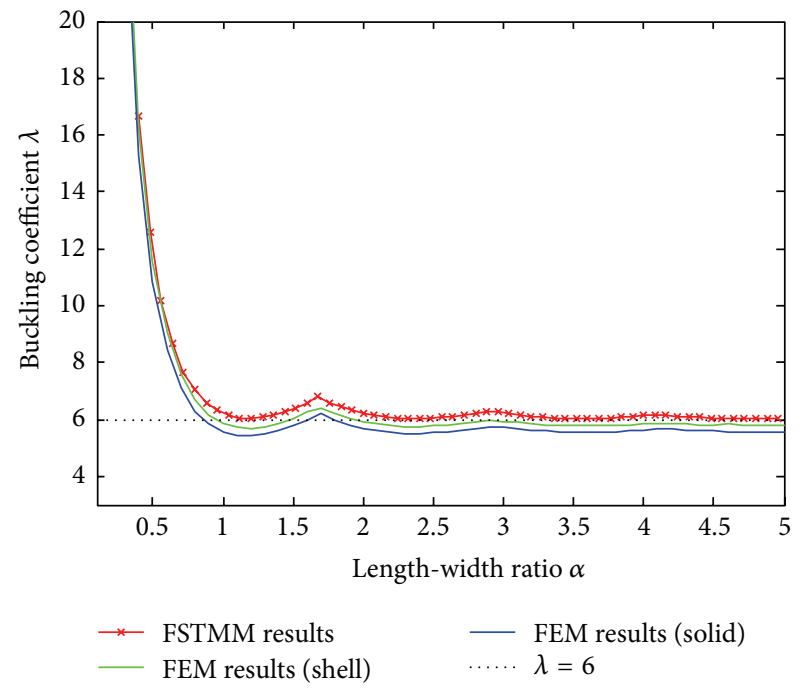

FIGURE 5: Relations between $\lambda$ and $\alpha$ of the plate with three ribs and boundary conditions of SSss.

with the shell elements and solid elements, as shown in Figure 5. Three curves have similar variation tendency which proves FSTMM can also be credible in the buckling analysis 


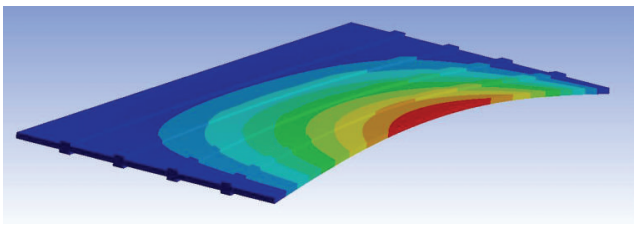

(a) Length-width ratio $\alpha=2$

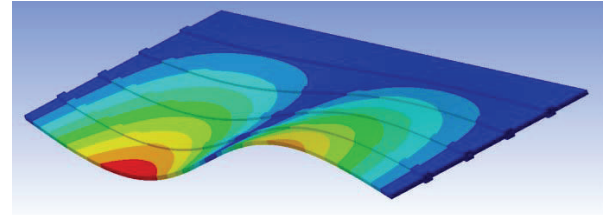

(b) Length-width ratio $\alpha=3.5$

FIGURE 6: Buckling deformation mode of the plate with four ribs and boundary bonditions of SSfc.

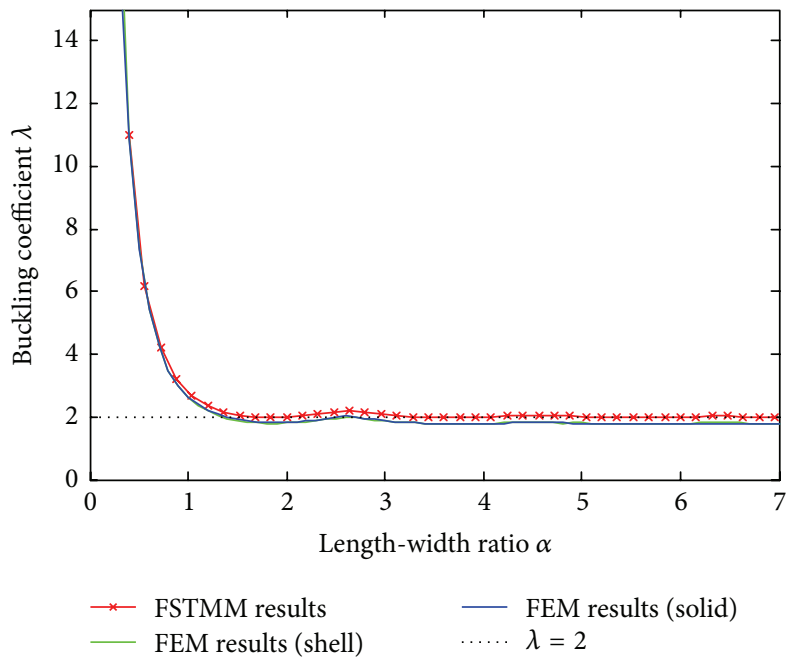

FIgURE 7: Relations between $\lambda$ and $\alpha$ of the plate with four ribs and boundary conditions of SSfc.

of the ribbed plate. And there is an obvious difference about the computational consumption that depends on the element number among these three methods shown in Figure 3. So the proposed method is highly efficient. Furthermore, the buckling coefficient of FEM with solid model is always smaller than that of FEM with shell model, and the buckling coefficient of FEM with shell model is always smaller than that of FSTMM; the reason is that the shear strain is generally included in the FEM analysis with solid elements and partly included in the analysis with the FEM's shell elements while neglected in the FSTMM analysis. It also indicates that the classical Kirchhoff assumption in the plate theory will make the critical buckling loads a bit larger than the true results. Comparing with Figures 2(a) and 5, the buckling coefficients converge to, 4 and 6 respectively, when $\alpha$ increases. We can obviously find that the plate can be stiffened by the ribs.

4.2.2. Plate with Four Ribs. The material properties are the same as stated in the former chapter. The geometrical parameters are as follows. The width of the plate is $5 \mathrm{~mm}$ and the thickness is $0.1 \mathrm{~mm}$. The ribs are $0.2 \mathrm{~mm}$ in width and $0.2 \mathrm{~mm}$ in thickness. Four ribs are uniformly spaced along the transverse direction; the width of the internal space is $0.84 \mathrm{~mm}$. The length of the plate is a variable parameter ranged from $0.5 \mathrm{~mm}$ to $35 \mathrm{~mm}$. In shell model of FEM and FSTMM, the initial axial force of the plate is $7.2305 \mathrm{~N} / \mathrm{mm}$ and the initial axial force of ribs is $14.461 \mathrm{~N} / \mathrm{mm}$. In solid model of FEM, the initial axial pressure in the cross section is $72.305 \mathrm{MPa}$.
Then the loading forces of the shell and solid models are equivalent. The plate is simply supported in loaded edges, while two unloaded edges are free and clapped separately.

Figure 6(a) shows the buckling deformation of a plate with four ribs and boundary conditions of SSfc when the length is $10 \mathrm{~mm}$; in other words, the length-width ratio is 2 . Figure 6(b) shows the buckling deformation of a plate with the length $17.5 \mathrm{~mm}$ (length-width ratio 3.5). As to the case of Figure 6(a) (or Figure 6(b)), this critical buckling configuration includes one (two) half-wave(s) model. Actually, the minimal critical buckling load can be obtained by setting the half-wave number $p=1$ (or $p=2$ ) in the FSTMM. The value of the half-wave number $p$ can be used to distinguish the buckling models of the plate which is convenient for the suppression of the instable failure.

In Figure 7, three curves obtained by three different methods give the relationship between buckling coefficient and length-width ratio of the four-ribbed plate with boundary conditions of SSfc. The good agreement among the three results shown in Figures 5 and 7 indicates that the proposed FSTMM can be used in the buckling analysis of the plate with several ribs and different boundary conditions.

4.3. Comparative Analysis. As a general rule, the computational precision can be improved by increasing the number of the elements. Here the influence of the element number to the computational precision can be analyzed if FEM's shell model and FSTMM are applied to calculate the buckling problems 


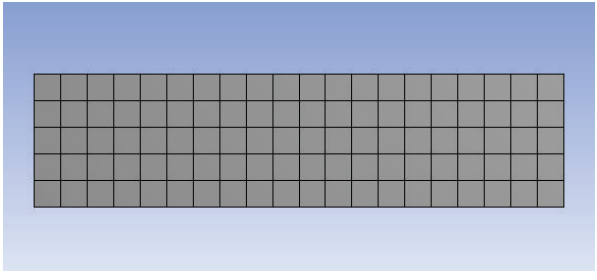

(a) 100 square elements

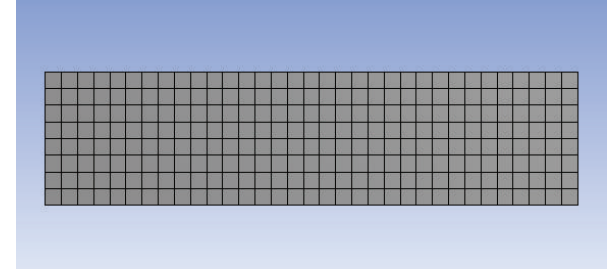

(b) 264 square elements

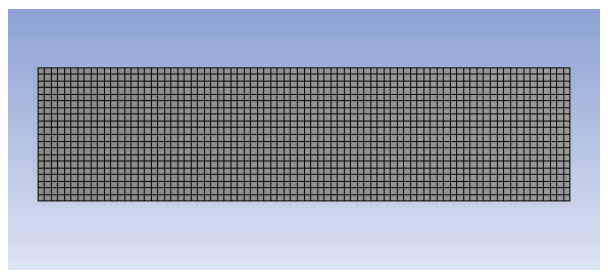

(c) 1600 square elements

FIGURE 8: Three mesh sizes in FEM for the same plate.

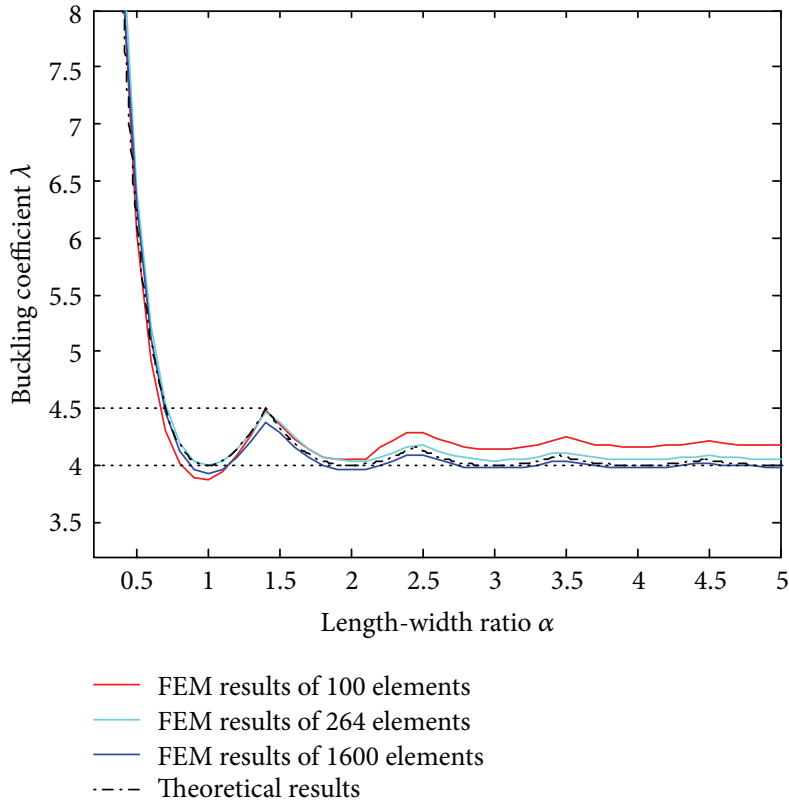

(a) Results of FEM

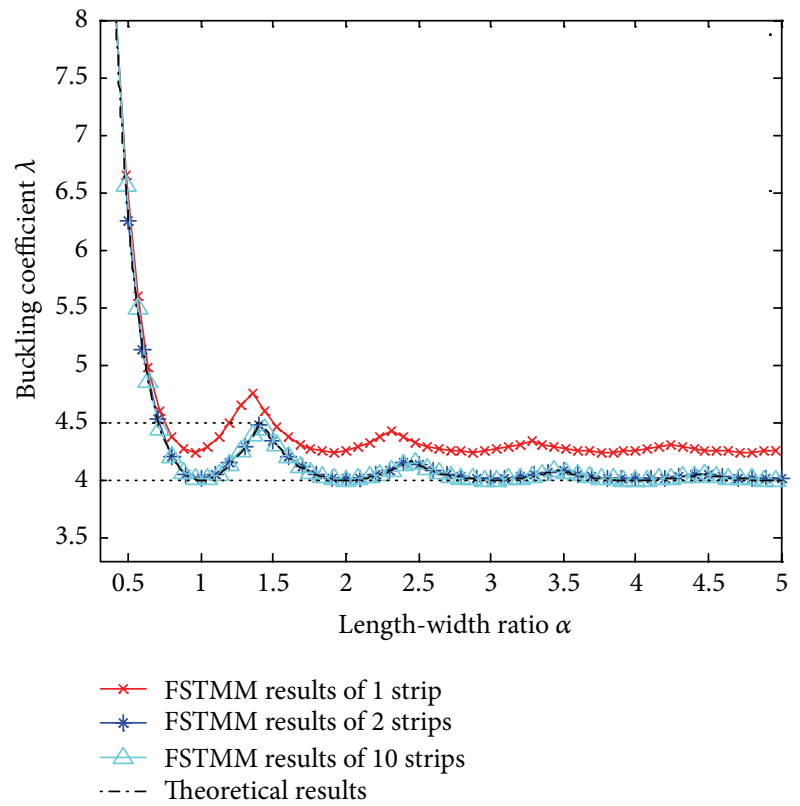

(b) Results of FSTMM

FIGURE 9: Relations between $\lambda$ and $\alpha$ of the plate with boundary conditions of SSss by using three mesh sizes.

of thin plate with the boundary conditions of SSss. The buckling behaviors can be obtained by the FEM's shell model with different mesh sizes which are shown in Figures 8(a), $8(\mathrm{~b})$, and 8(c) with the element numbers 100,264 , and 1600 , respectively.

Figure 9 compares the influence of the element number to the computational precision in FEM's shell model and FSTMM. In order to make the errors between the FEM's and theoretical results acceptable, the element number may increase unexpectedly from 100, 264 to 1600 , as shown in Figure 9(a). In contrast with this performance of the FEM, as the number of strips $n=2$ in FSTMM is selected, the computational results have good agreement with the theoretical results, as shown in Figure 9(b). So it may be confirmed that the proposed FSTMM has good efficiency for the buckling analysis of rectangular thin plates under the boundary condition of simply supported loaded edges.

\section{Conclusions}

In this investigation, the semi-analytical Finite Strip Transfer Matrix Method is proposed to analyze the buckling problems of rectangular thin plates under the boundary condition of simply supported loaded edges. In order to validate the method, the examples of the plate and the plate with ribs can be designed and analyzed by different methods. 
It may be found that the method holds several highlights: (1) it demands no global stiffness matrix and reduces matrix order in the system analysis, (2) the orthogonality among the analytical shape functions of the loaded direction of the plate leads to the clear computational mode of the buckling analysis, (3) both the semi-analytical finite strip and the transfer matrix technologies ensure the proposed method efficient.

\section{Conflict of Interests}

The authors declare that there is no conflict of interests regarding the publication of this paper.

\section{Acknowledgment}

The research is financed by National Key Science Foundation Program (51624001), Natural Science Foundation of Jiangsu Province, China (BK20130911).

\section{References}

[1] S. P. Timoshenko and S. Woinowsky-Krieger, Theory of Plates and Shells, McGraw-Hill, New York, NY, USA, 1959.

[2] J. N. Reddy, Mechanics of Laminated Composite Plates and Shells: Theory and Analysis, CRC Press, New York, NY, USA, 2004.

[3] J. Rhodes, "Buckling of thin plates and members-and early work on rectangular tubes," Thin-Walled Structures, vol. 40, no. 2, pp. 87-108, 2002.

[4] R. E. Kielb and L. S. Han, "Vibration and buckling of rectangular plates under in-plane hydrostatic loading," Journal of Sound and Vibration, vol. 70, no. 4, pp. 543-555, 1980.

[5] S. Takeshi and M. Hiroshi, "Elastic buckling of rectangular mindlin plate with mixed boundary conditions," Computers \& Structures, vol. 25, no. 5, pp. 801-808, 1987.

[6] Y. Narita and A. W. Leissa, "Buckling studies for simply supported symmetrically laminated rectangular plates," International Journal of Mechanical Sciences, vol. 32, no. 11, pp. 909-924, 1990.

[7] I. E. Harik and N. Balakrishnan, "Stability of orthotropic rectangular plates," Applied Mathematical Modelling, vol. 18, no. 7, pp. 400-402, 1994.

[8] Y.Z. Chen, "Evaluation of buckling loading of rectangular bending plate by using an iterative approach," Computer Methods in Applied Mechanics and Engineering, vol. 167, no. 1-2, pp. 91-99, 1998.

[9] S. Yuan and Y. Jin, "Computation of elastic buckling loads of rectangular thin plates using the extended Kantorovich method," Computers \& Structures, vol. 66, no. 6, pp. 861-867, 1998.

[10] T. M. Teo and K. M. Liew, "A differential quadrature procedure for three-dimensional buckling analysis of rectangular plates," International Journal of Solids and Structures, vol. 36, no. 8, pp. 1149-1168, 1998.

[11] C.-P. Wu, Y.-M. Wang, and Y.-C. Hung, "Asymptotic finite strip analysis of doubly curved laminated shells," Computational Mechanics, vol. 27, no. 2, pp. 107-118, 2001.

[12] C.-S. Chien, S.-L. Chang, and Z. Mei, "Tracing the buckling of a rectangular plate with the Block GMRES method," Journal of Computational and Applied Mathematics, vol. 136, no. 1-2, pp. 199-218, 2001.
[13] J. Wang, K. M. Liew, M. J. Tan, and S. Rajendran, "Analysis of rectangular laminated composite plates via FSDT meshless method," International Journal of Mechanical Sciences, vol. 44, no. 7, pp. 1275-1293, 2002.

[14] K. M. Liew and X. L. Chen, "Buckling of rectangular Mindlin plates subjected to partial in-plane edge loads using the radial point interpolation method," International Journal of Solids and Structures, vol. 41, no. 5-6, pp. 1677-1695, 2004.

[15] S. Kshirsagar and K. Bhaskar, "Accurate and elegant free vibration and buckling studies of orthotropic rectangular plates using untruncated infinite series," Journal of Sound and Vibration, vol. 314, no. 3-5, pp. 837-850, 2008.

[16] Ö. Civalek, A. Korkmaz, and Ç. Demir, "Discrete singular convolution approach for buckling analysis of rectangular Kirchhoff plates subjected to compressive loads on two-opposite edges," Advances in Engineering Software, vol. 41, no. 4, pp. 557$560,2010$.

[17] O. Vaseghi, H. R. Mirdamadi, and D. Panahandeh-Shahraki, "Non-linear stability analysis of laminated composite plates on one-sided foundation by hierarchical Rayleigh-Ritz and finite elements," International Journal of Non-Linear Mechanics, vol. 57, pp. 65-74, 2013.

[18] F. Millar and D. Mora, "A finite element method for the buckling problem of simply supported Kirchhoff plates," Journal of Computational and Applied Mathematics, vol. 286, pp. 68-78, 2015.

[19] Y. K. Cheung, L. G. Tham, and W. Y. Li, "Free vibration and static analysis of general plate by spline finite strip," Computational Mechanics, vol. 3, no. 3, pp. 187-197, 1988.

[20] T. Mizusawa, "Buckling of rectangular Midlin plates with tapered thickness by the spline strip method," International Journal of Solids and Structures, vol. 30, no. 12, pp. 1663-1677, 1993.

[21] D. J. Dawe and S. Wang, "Spline finite strip analysis of the buckling and vibration of rectangular composite laminated plates," International Journal of Mechanical Sciences, vol. 37, no. 6, pp. 645-667, 1995.

[22] W. J. Wang, Y. P. Tseng, and K. J. Lin, "Stability of laminated plates using finite strip method based on a higher-order plate theory," Composite Structures, vol. 34, no. 1, pp. 65-76, 1996.

[23] S. Wang and D. J. Dawe, "Buckling of composite shell structures using the spline finite strip method," Composites Part B: Engineering, vol. 30, no. 4, pp. 351-364, 1999.

[24] W.-C. Xie and A. Ibrahim, "Buckling mode localization in rib-stiffened plates with misplaced stiffeners-a finite strip approach," Chaos, Solitons \& Fractals, vol. 11, no. 10, pp. 1543$1558,2000$.

[25] Y. K. Cheung and L. G. Tham, "A review of the finite strip method," Progress in Structural Engineering and Materials, vol. 2, no. 3, pp. 369-375, 2000.

[26] S. Wang and Y. Zhang, "Vibration analysis of rectangular composite laminated plates using layerwise B-spline finite strip method," Composite Structures, vol. 68, no. 3, pp. 349-358, 2005.

[27] L. Yongqiang, "Free vibration analysis of plate using finite strip Fourier p-element," Journal of Sound and Vibration, vol. 294, no. 4, pp. 1051-1059, 2006.

[28] H. R. Ovesy and H. Assaee, "An investigation on the postbuckling behavior of symmetric cross-ply laminated plates using a semi-energy finite strip approach," Composite Structures, vol. 71, no. 3-4, pp. 365-370, 2005.

[29] H. Assaee and H. R. Ovesy, "A multi-term semi-energy finite strip method for post-buckling analysis of composite plates," 
International Journal for Numerical Methods in Engineering, vol. 70, no. 11, pp. 1303-1323, 2007.

[30] H. R. Ovesy and J. Fazilati, "Stability analysis of composite laminated plate and cylindrical shell structures using semianalytical finite strip method," Composite Structures, vol. 89, no. 3, pp. 467-474, 2009.

[31] H. R. Ovesy, A. Totounferoush, and S. A. M. Ghannadpour, "Dynamic buckling analysis of delaminated composite plates using semi-analytical finite strip method," Journal of Sound and Vibration, vol. 343, pp. 131-143, 2015.

[32] S. Tarasovs and J. Andersons, "Buckling of a coating strip of finite width bonded to elastic half-space," International Journal of Solids and Structures, vol. 45, no. 2, pp. 593-600, 2008.

[33] H. C. Bui, "Semi-analytical finite strip method based on the shallow shell theory in buckling analysis of cold-formed sections," Thin-Walled Structures, vol. 50, no. 1, pp. 141-146, 2012.

[34] G. J. Hancock and C. H. Pham, "Buckling analysis of thin-walled sections under localised loading using the semi-analytical finite strip method," Thin-Walled Structures, vol. 86, pp. 35-46, 2015.

[35] S. Ádány and B. W. Schafer, "Buckling mode decomposition of single-branched open cross-section members via finite strip method: derivation," Thin-Walled Structures, vol. 44, no. 5, pp. 563-584, 2006.

[36] S. Ádány and B. W. Schafer, "Buckling mode decomposition of single-branched open cross-section members via finite strip method: application and examples," Thin-Walled Structures, vol. 44, no. 5, pp. 585-600, 2006.

[37] Z. Li, J. C. Batista Abreu, J. Leng, S. Ádány, and B. W. Schafer, "Review: constrained finite strip method developments and applications in cold-formed steel design," Thin-Walled Structures, vol. 81, pp. 2-18, 2014.

[38] S. Ádány and B. W. Schafer, "Generalized constrained finite strip method for thin-walled members with arbitrary cross-section: secondary modes, orthogonality, examples," Thin-Walled Structures, vol. 84, pp. 123-133, 2014.

[39] S. Ádány and B. W. Schafer, "Generalized constrained finite strip method for thin-walled members with arbitrary cross-section: primary modes," Thin-Walled Structures, vol. 84, pp. 150-169, 2014.

[40] Z. Li, M. T. Hanna, S. Ádány, and B. W. Schafer, "Impact of basis, orthogonalization, and normalization on the constrained Finite Strip Method for stability solutions of open thin-walled members," Thin-Walled Structures, vol. 49, no. 9, pp. 1108-1122, 2011.

[41] R. Uhrig, "The transfer matrix method seen as one method of structural analysis among others," Journal of Sound and Vibration, vol. 4, no. 2, pp. 136-148, 1966.

[42] T. J. McDaniel and K. B. Eversole, "A combined finite elementtransfer matrix structural analysis method," Journal of Sound and Vibration, vol. 51, no. 2, pp. 157-169, 1977.

[43] G. Chiatti and A. Sestieri, "Analysis of static and dynamic structural problems by a combined finite element-transfer matrix method," Journal of Sound and Vibration, vol. 67, no. 1, pp. 3542, 1979.

[44] M. Ohga, T. Shigematsu, and T. Hara, "Structural analysis by a combined boundary element-transfer matrix method," Computers \& Structures, vol. 24, no. 3, pp. 385-389, 1986.

[45] M. Ohga and T. Shigematsu, "Analysis of continuous plates by a combined boundary element-transfer matrix method," Computers \& Structures, vol. 36, no. 1, pp. 81-89, 1990.

[46] C. Yuhua, "Large deflection analysis of structures by an improved combined finite element-transfer matrix method," Computers \& Structures, vol. 55, no. 1, pp. 167-171, 1995.
[47] X. Rui, B. He, Y. Lu, W. Lu, and G. Wang, "Discrete time transfer matrix method for multibody system dynamics," Multibody System Dynamics, vol. 14, no. 3-4, pp. 317-344, 2005.

[48] B. Rong, "Efficient dynamics analysis of large-deformation flexible beams by using the absolute nodal coordinate transfer matrix method," Multibody System Dynamics, vol. 32, no. 4, pp. 535-549, 2014.

[49] F. Chevillotte and R. Panneton, "Coupling transfer matrix method to finite element method for analyzing the acoustics of complex hollow body networks," Applied Acoustics, vol. 72, no. 12, pp. 962-968, 2011.

[50] D. Li, G. Tang, J. Zhou, and Y. Lei, "Buckling analysis of a plate with built-in rectangular delamination by strip distributed transfer function method," Acta Mechanica, vol. 176, no. 3-4, pp. 231-243, 2005.

[51] Y. Kang, Y.-G. Lee, and S.-C. Chen, "Instability analysis of unsymmetrical rotor-bearing systems using the transfer matrix method," Journal of Sound and Vibration, vol. 199, no. 3, pp. 381400, 1997.

[52] E. S. Kameshki and S. Syngellakis, "Inelastic stability of rectangular frames by transfer matrices," Computers \& Structures, vol. 73, no. 1-5, pp. 373-383, 1999.

[53] M. A. Bradford and M. Azhari, "Buckling of plates with different end conditions using the finite strip method," Computers \& Structures, vol. 56, no. 1, pp. 75-83, 1995.

[54] E. Ruocco and M. Fraldi, "Critical behavior of flat and stiffened shell structures through different kinematical models: a comparative investigation," Thin-Walled Structures, vol. 60, pp. 205215, 2012. 


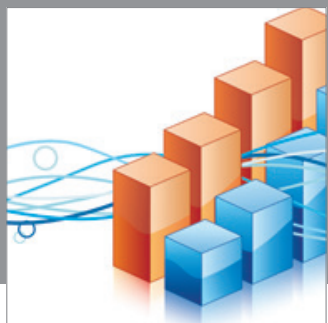

Advances in

Operations Research

mansans

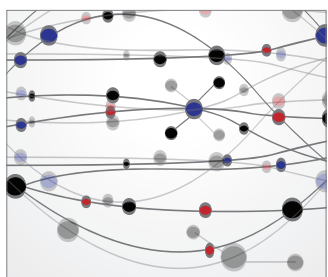

The Scientific World Journal
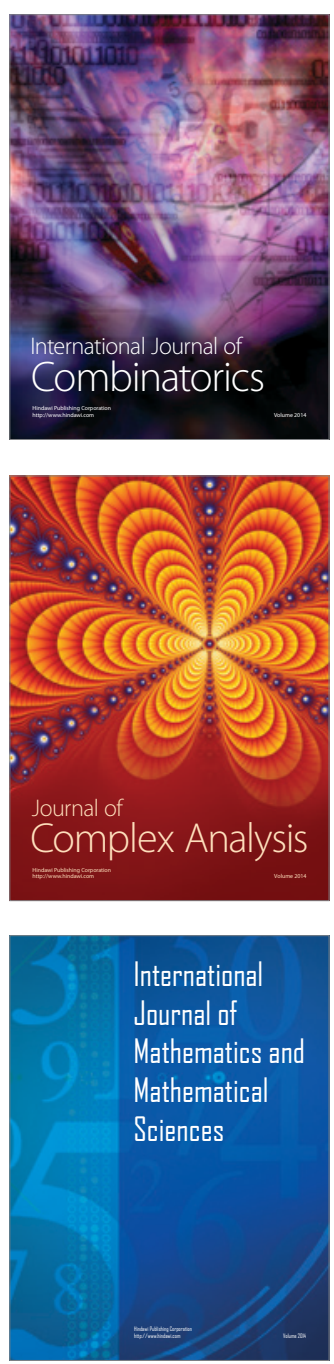
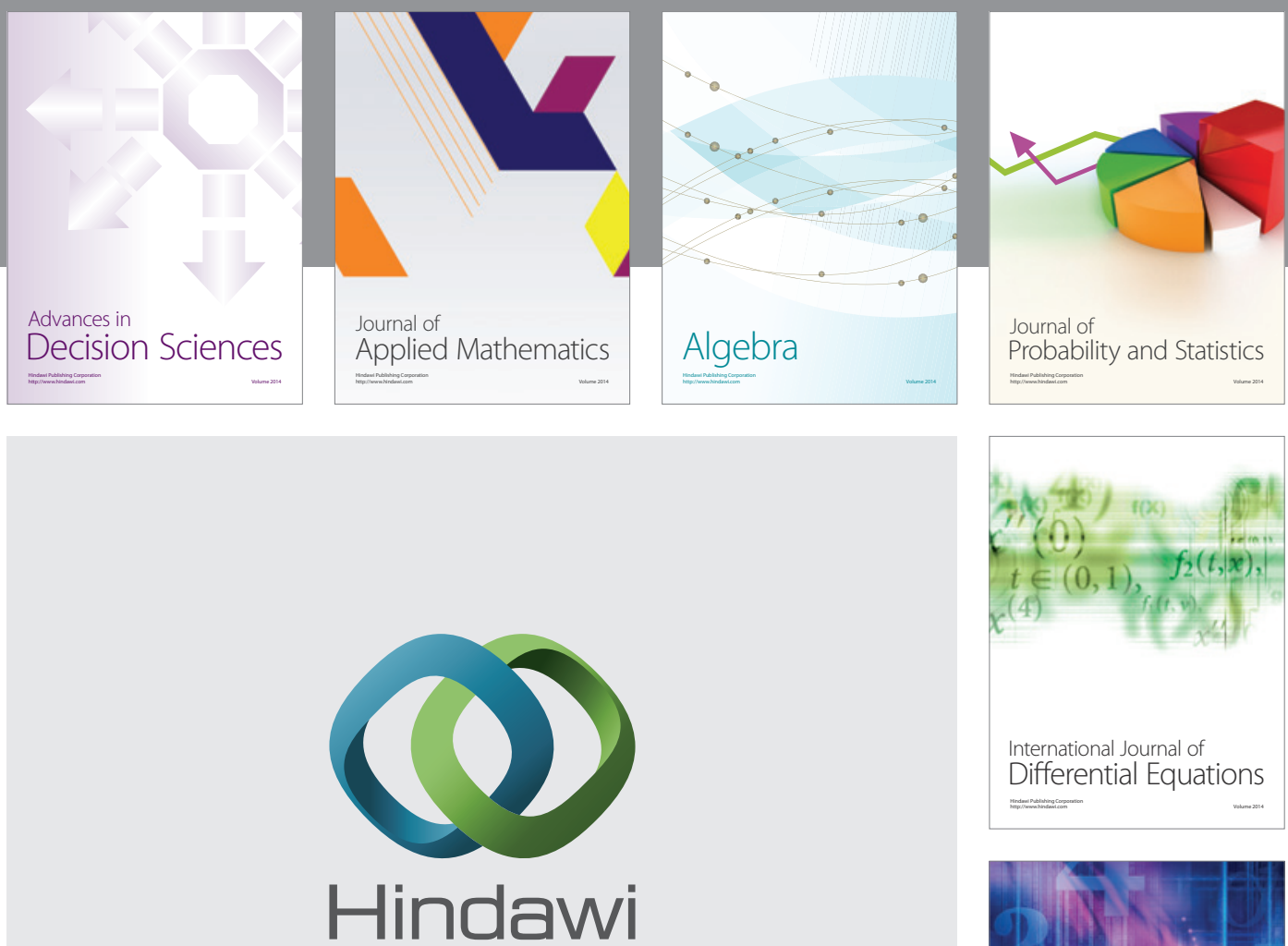

Submit your manuscripts at http://www.hindawi.com
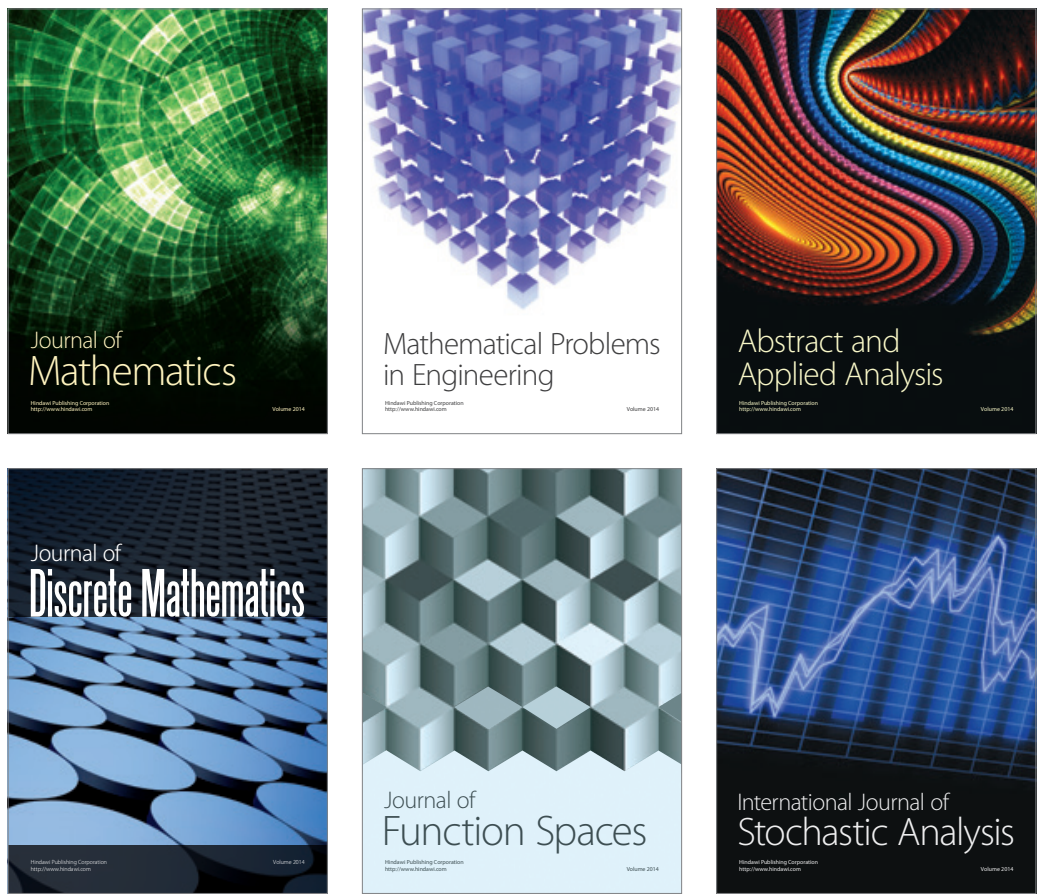

Journal of

Function Spaces

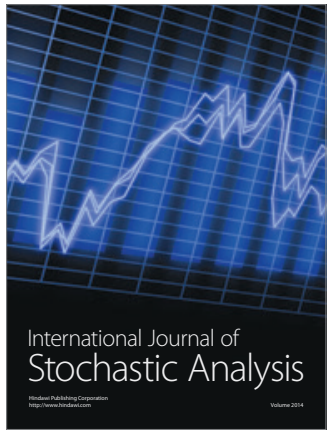

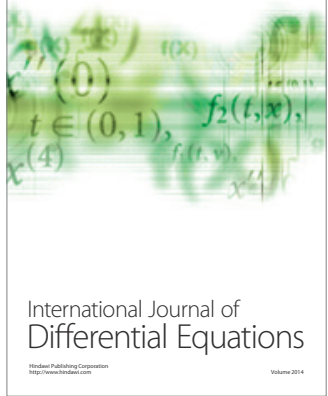
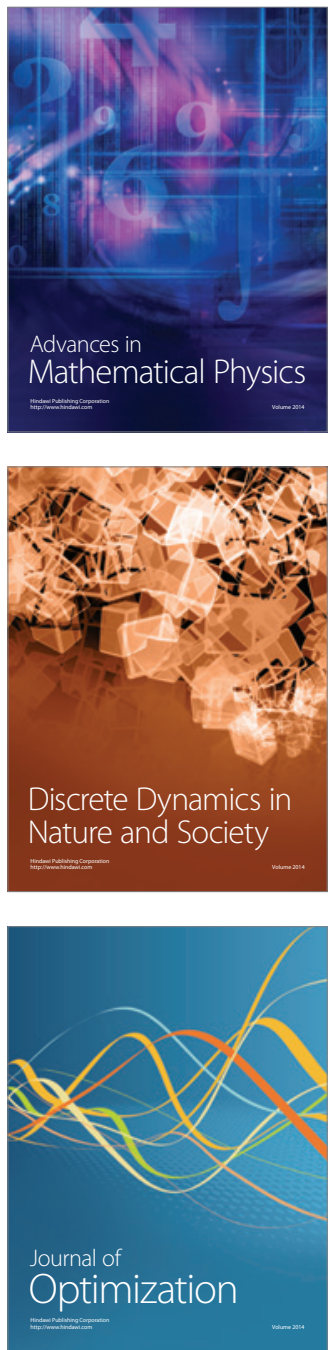